\title{
TECENDO TRICKSTERS: MULTIVOCALIZAÇÃO NARRATIVA E ANIMALIZAÇ̃̃O EM THE ANTELOPE WIFE, DE LOUISE ERDRICH
}

\author{
WEAVING TRICKSTERS: NARRATIVE MULTIVOCALIZATION AND ANIMALIZATION IN LOUISE ERDRICH'S THE \\ ANTELOPE WIIE
}

\section{RESUMO}

Esta pesquisa tem o intuito de investigar a categoria trickster e suas possibilidades de agenciamento no romance da nativo-americana Louise Erdrich, The Antelope Wife (1998). Baseamos nossas epistemes, fundamentalmente, em aparatos teóricofilosóficos que discutem o lugar de nativo-americanas/os e a decolonialidade, em autoras/es como: Cunha (2014); Gates Jr. (1988); Vizenor (1990) e Schneider (2001). Percebemos formas diferentes de tricksters no referido romance que agenciam relações de poder, ora subvertendo-as, ora transgredindo-as. Em The Antelope Wife, a storytelling, evidenciada no discurso da narradora central e nas focalizações em várias personagens, traz uma multivocalização narrativa que subverte a ordem linear da narratividade e transgride os discursos hegemônicos das narrativas de fundação, de forma metonímica na relação animal-homem. Sendo assim, em diferentes multiestéticas, a trickster do romance convergem no sentido de estabelecerem lugares de fala diversos e compõem um acervo produzido por povos contra hegemônicos que se circunscrevem nas Américas de povos nativos.

Palavras-chave: Trickster. Multivocalização Narrativa. Animalização. Narrativas Nativo-Americanas. The Antelope Wife.

\begin{abstract}
This research aims to investigate the trickster category and its agency possibilities in the Native American Louise Erdrich's novel, The Antelope Wife (1998). We base our epistemes fundamentally on theoretical-philosophical apparatuses that discuss the place of Native Americans and decoloniality, on authors such as: Cunha (2014); Gates Jr. (1988); Vizenor (1990), and Schneider (2001). We perceive different forms of tricksters in the novel that broke power relations, sometimes subverting them, sometimes transgressing them. In The Antelope Wife, storytelling, evidenced in the central narrator's discourse and focus on various characters, brings a narrative multivocalization that subverts the linear order of narrativity and transgresses the hegemonic discourses of the founding narratives in a metonymic way in the animalman relationship. . Thus, in different multi-aesthetics, the trickster of the novel converge to establish diverse places of speech and make up a collection produced by counter-hegemonic peoples that are circumscribed in the Americas by native peoples.
\end{abstract}

Monaliza Rios Silva

UFRPE, Brasil. E-mail: monaliza_rios@yahoo.com.br 
Keywords: Trickster. Narrative Multivocalization. Animalization. Native American Narratives. The Antelope Wife.

\section{Introdução}

Matilda Roy, personagem do romance The Antelope Wife, de Louise Erdrich (1998), foi criada por um homem que a amamentou. Isso está atrelado a seu lado humano, seu pai, sua referência de amor. Percebemos instinto selvagem, em seu sentido mítico e ontológico: a relação profunda entre o ser humano e a natureza. Partindo de uma ambiência em que a cultura se entrelaça com o espaço in natura, anunciamos que entramos em uma atmosfera em que o mí(s)tico, do campo do simbólico, intrinca-se ao campo cultural e literário.

Intencionamos ilustrar, com o anteriormente mencionado, de que lugar falamos ao nos referirmos à análise do romance já referido, de Erdrich. Além de apontar o caráter da ligação e/ou sobreposição ser humano-animal que povoa o storytelling de matriz nativo-americana. No que se refere à organização comunitária, os "[...] indigenous people of the Americas formed oral communities. Natives relied on memory, their stories and myths being told over and over again, first because they were seen as creative and formative, but also in order not to be forgotten" (SCHNEIDER, 2001:40, grifo nosso). Considerando o trecho em destaque, entendemos que a prática do storytelling se configura como um ato de resistência e marcação identitária desses povos em um território parcialmente tomado pelo outsider, que de várias formas tentaram apagar traços importantes das culturas originais.

\section{Fundamentação Teórica}

Do ponto de vista do mundo ocidental, torna-se difícil uma abordagem do ser humano como uma parte constituinte da natureza, não como centro desta. Para as análises desta obra é imprescindível compreender que partimos de um lugar que rompe com o paradigma cartesiano e antropocêntrico da concepção do humano. Diferente disso, devemos compreender como o ser humano tem se relacionado com a natureza, os animais e os espaços. Em primeira instância, a ideia de que a natureza é um ambiente externo ao homem com o qual este se relaciona é estanque e não se encaixa ao nosso corpus, pelas perspectivas críticas que abordamos. Primeiro porque o ser humano, per si, já possui uma natureza e esta se comunica com tudo que o circunda.

O filósofo contemporâneo alemão Peter Sloterdijk (1947-), em seu Regras para o Parque Humano (200o), problematiza o conceito de humanismo ao longo da Filosofia ocidental e traz algumas inquietações, por exemplo, a respeito do heideggerianismo e os conceitos de ôntico (o ente, o existente múltiplo e concreto) e de ontológico 
(essência ou natureza geral do existente). Quanto ao humanismo, Sloterdijk (200o) afirma:

O fenômeno do humanismo hoje merece atenção antes de mais nada porque nos recorda - embora de forma velada e tímida que as pessoas na cultura elitizada estão submetidas de forma constante e simultânea a dois poderes de formação - vamos aqui denominá-los, para simplificar, influências inibidoras e desinibidoras. Faz parte do credo do humanismo a convicção de que os seres humanos são "animais influenciáveis" e de que é, portanto, imperativo prover-lhes o tipo certo de influências. A etiqueta "humanismo" recorda - de forma falsamente inofensiva - a contínua batalha pelo ser humano que se produz como disputa entre tendências bestializadoras e tendências domesticadoras (SLOTERDIJK, 2000: 17).

A perspectiva do ôntico particulariza o existente (ente) e a perspectiva do ontológico maximiza o olhar, questionando e refletindo sobre o relacional do todo que existe ao redor, de acordo com Chauí, discutindo as ideias de Heidegger. Desta forma, o ser humano, como ente do humanismo, destaca-se de tudo o que mais existe e se torna o centro da própria existência. Heidegger, em Cartas sobre o Humanismo (1947), afirma que se volta contra o humanismo, desde seu Ser e Tempo (1927) pelo fato do conceito de humanistas não ter atribuído "valor suficientemente elevado" à questão da essência do ser humano, ao colocar o homem como "animal rationale", pois este continua sendo entendido como "animalitas". Para Heidegger "a essência do ser humano não pode jamais ser expressa em uma perspectiva zoológica ou biológica mesmo que a ela se acresça regularmente um valor espiritual ou transcendente" (SLOTERDIJK, 2000: 25).

Essa tentativa de compreender o ser humano pelo sentido ôntico-ontológico, portanto, singularizado de Heidegger dá fundamentos para o questionamento de Sloterdijk (200o): "o que ainda domestica o homem, se o humanismo naufragou como escola da domesticação humana?” (SLOTERDIJK, 2000: 32). Sloterdijk argumenta que se pode falar sob duas perspectivas: 1- história natural da serenidade, em que "o ser humano pôde se tornar um animal aberto e capaz para o mundo" (SLOTERDIJK, 2000: 33); 2- história social das domesticações, em que "os homens originalmente se experimentam como aqueles seres que se reúnem para corresponder ao todo" (SLOTERDIJK, 2000: 33).

Como o animal spaiens se tornou o homem sapiens é explicado por meio da domesticação e na educação para o sedimentarismo, com vias a encaixar na "casa do ser" (termos de Heidegger) que é a linguagem. Em outras palavras: o ser humano fracassou em ser animal e em permanecer animal. Sloterdijk (2000, p. 34) continua sua tese e afirma: "ao fracassar como animal, esse ser indeterminado tomba para fora de seu ambiente e com isso ganha o mundo no sentido ontológico". Se para Heidegger, 
negar a raiz animal na concepção do ser humano coloca o homem ${ }^{1}$ no mundo; para Sloterdijk compreender o ser humano como a parte do animal é destituí-lo da própria existência no mundo ou, deslocá-lo de seu estar-no-mundo.

Muito consonante com Sloterdijk (200o), o filósofo italiano Giorgio Agamben (1942-), em O Aberto: o homem e o animal (2004), faz crítica sobre as várias concepções acerca do homem (sic.) e atribui à biofilosofia e às ciências do homem as responsáveis por conceituar e legislar sobre o homem, decidindo sobre qual(s) forma(s) da política e da moral se deve dispor sobre a ordem, sobre o controle de grupos de homens. Além disso, os esforços de Agamben (2004) são focados na discussão do aberto, partindo da premissa de que pensar sobre o homem é entender a "biofilosofia dos graus do orgânico" que se situam em movimento e que são cada vez mais imprecisos à medida que se tenta distinguir o limite entre o homem e o animal.

Sendo assim, entendemos que o pensamento fenomenológico-existencial de supremacia do ser humano na natureza reforça um abismo no entendimento do próprio ser humano e de como este está e é no mundo, afastado de sua corporalidade e subjetividade, uma vez que se elege um padrão unilateral do que é o homem como regimento de um ser que se encontra em movimento e em constantes transições em sua existência. Muitas epistemologias sobre o assunto têm surgido e questionam o pensamento ocidental sobre o homem e já anuncia uma incipiente quebra paradigmática: a transposição do corpo físico. O que, grosso modo, diz respeito às (trans)concepções das fronteiras corpóreas dos seres e das coisas no mundo.

Continuando no mesmo tema, Stacy Alaimo (2017), em seu Feminismos Transcorpóreos e o Espaço Ético da Natureza, discute que a teoria feminista, nas últimas décadas, tende a destacar a cultura em detrimento da materialidade (o biológico). A pesquisadora estadunidense problematiza o conceito de natureza que as teorias feministas da construção social trazem que, segundo a autora, é "repositório de essencialismo e stasis" (ALAIMO, 2017: 911). Além disso, Alaimo defende a tese de que o corpo deveria ser entendido como "mutante e mutável, como transformável" (BIRKE, 1999 apud ALAIMO, 2017: 913) e não fixado no aparato determinado biologicamente. Não se faz pauta de nossos interesses, contudo, as polêmicas discussões que Alaimo aponta em relação à questão de gênero/sexo, tão cara às teorias feministas até então produzidas. Enfatizamos o argumento da transcorporalidade dos seres nos cinco reinos, partindo do biológico, mas não se fixando nele.

Ressaltamos a necessidade de se trazer essas breves considerações sobre humano-animal-natureza como forma de tornar conhecidos os principais argumentos $^{3}$ do romance que protagonizará as análises desta pesquisa. Ao retirar essas novas epistemologias do lugar do estranhamento, reforçamos que esses

1 À época o humano era pensado no masculino e apenas por isso utilizamos o termo mencionado nas teorias.

2 Pelo contexto em que Alaimo (2017) menciona, o termo tem o sentido de estado estático.

3 Para Julio Cortázar (In: Valise de Cronópio, 1974), o argumento é o tema, o assunto de uma realidade ficcional. Mais do que o clássico conceito de enredo, para o escritor argentino, o argumento é o discurso ficcional. 
discursos representam as vozes nativas que são silenciadas não apenas em suas formas de manifestação e simbologias, mas também em seu status de existência. Isto porque, uma vez não pertencendo aos pilares do pensamento ocidental (episteme), esse conhecimento é colocado no lugar da não existência ou do estranho.

Neste artigo objetivamos apresentar e discutir quais formas de Trickster estão presentes no romance The Antelope Wife, de Louise Erdrich (1998). Para tanto, trazemos uma investigação do romance mencionado, começando por uma análise da estrutura da narrativa até a problematização das formas de Trickster presentes em The Antelope Wife, através de discussões sobre o storyteling ${ }^{4}$ (multivocalização) e o processo de animalização.

\section{Análise e Discussões}

O romance está disposto em quatro partes: Parte 1 - "Bayzhig"; Parte 2 - "Neej"; Parte 3 - "Niswey"; Parte 4 - "Neewin" (um, dois, três e quatro, respectivamente, em Ojibwe - BEIDLER; BARTON, 2006, p. 382; 390; 391; 390). Para informação sobre fatos históricos que ajudam a compreender The Antelope Wife, segue excerto.

To enact the policy of forced acculturation, U.S. officials concentrated on young as well as adult members of Indian tribes. Education became the forum for reaching the young, or more exactly, the Indian boarding school. The same Captain Pratt who wanted to extinguish the existence of tribes came up with a practical means of doing so. He founded the Carlisle Indian School from a former military base in Pennsylvania in 1879, his aim being to "kill the Indian and save the man" in each student. At boarding schools, children were isolated from their families for several years at a time, forced to accept Christianity, and forbidden from speaking their own language or wearing customary dress. The Antelope Wife brings to mind these dictates of the missionaryrun boarding schools in the naming of twin daughters. The boarding school strategy seemed to U.S. authorities to be a wise one, and, following Pratt's example, they embraced it. By the late 1920 , less than 20 percent of native children were receiving traditional upbringing outside the boarding schools. Dr. Lyman Abbott articulated the rationale for boarding school policy in this keynote address at the Mohonk conference in 1888 "Education for the Indian": "Schools are less expensive than war. It costs less to educate an Indian than it does to shoot him" (WUB-E-KE-NIEW, 1995: 109 apud ABBOTT, 1998)5.

4 A permanência do termo em inglês é uma escolha, por fins de recuperar o significado mais amplo do termo, mais consonante com a fortuna crítica literária da literatura nativo-americana.

5 ABBOTT, Lyman (1998) The Antelope Wife: Literature and Its Times Supplement 1. Disponível em: <https://www.encyclopedia.com/arts/culture-magazines/antelope-wife>. Acesso em o7 jan. 2019. 
O longo excerto acima descreve uma política muito violenta e corrobora o que apresentamos no início desse capítulo sobre a construção de narrativas que estabelecem um grupo privilegiado e promove o apagamento identitário de outros grupos. O trecho deixa claro que a educação ocidentalizada é o meio de disseminar os padrões eurocêntricos e de silenciar a cultura nativo-americana. Indo na direção contrária, textos literários vinculam elementos culturais e defendemos algumas formas de trickster que aparecem em The Antelope Wife (ERDRICH, 1998) como meio de resistência contra as relações de poder opressoras, subvertendo ou transgredindo a ordem.

O espaço em que o enredo se desenrola é, basicamente, em uma vila Ojibwe no século XIX, provavelmente a oeste do Red River; em uma reserva em algum lugar ao norte, em Minneapolis; e nos anos 1990, em Minneapolis (BEIDLER; BRANTON, 2006). Os personagens interagem entre si e entre alguns membros de famílias, a saber: os Roy, os Shawano e os Whiteheart Beads. A primeira parte do romance destaca a dizimação de uma vila Ojibwe nas pradarias a oeste, provavelmente em North Dakota e já anuncia a escrita como registro de memória: "What happened to him [Scranton Roy] lives on, though fading in the larger memory, and I relate it here in order that it not be lost" (ERDRICH, 1998: 03). Além do registro da memória, percebemos o storytelling demarcando essa memória. No enunciado: "eu relato aqui para que não se perca” denota a resistência de um povo de não cair no ostracismo. Este último entendido como um dos projetos da colonização que era a aculturação de elementos culturais dos povos "vencidos": "a aculturação é, sem dúvida, o tema por excelência da antropologia colonial” (BOSI, 1992, p. 46).

Segundo o crítico brasileiro, o apagamento de aspectos culturais de indígenas ou de negros não resultava em proveito para o branco. Assim, havia um interesse do colonizador em manter sob seu jugo o acervo cultural produzido pelos povos "conquistados", porém sob controle. Assim, o autor chama a atenção para os "encontros que matam": essa intersecção cultural não se dá harmoniosamente. Por um caráter de supremacia branca, os discursos do poder hegemônico vão agindo no sentido de implementar o paradigma eurocêntrico nas colônias. Dessa feita, entendemos que "à primeira vista, a cultura letrada parece repetir, sem alternativa, o modelo europeu; mas, posta em situação, em face do índio, ela é estimulada, para não dizer constrangida, a inventar" (BOSI, 1992: 30-31): o colonizador se apropria da língua do nativo para vincular os valores, costumes e crenças europeus. Portanto, o processo de "assimilação" é um encontro que mata e a resistência dessas vozes constitui o sopro para a vida.

Segundo Beidler; Branton (2006), a voz narrativa do trecho de The Antelope Wife acima, provavelmente, a de Cally Roy, a tataraneta do soldado da cavalaria, Scranton Roy, uma vez que esta personagem anuncia algumas vezes o protagonismo de contar a estória: "I was sent here to understand and to report" (ERDRICH, 1998: 220). Na verdade, há uma estrutura misturada nas narrações, conotando o intercruzamento de membros dessas famílias e os variados pontos de vista (vozes narrativas) presentes. Isto confere uma aparente desordem na diegese, porém 
representa as múltiplas narrativas produzidas sobre um povo ou pelo próprio povo, através da memória guardada e relatada dos ancestrais.

Observamos em The Antelope Wife (1998), de Louise Erdrich, uma narrativa da confluência de raças e de estórias que gerenciam um espaço híbrido. O romance começa com uma costura de cores, de maneira "In, out, fast and furious" (ERDRICH, 1998: o1) e que foram feitas para "upset the balance of the world" (op. cit.: o1).

Trazemos para debate o "espetáculo das raças" (para usar o termo de Schwarcz, 1993) reconhecível em algumas personagens do romance citado, sendo Matilda Roy (uma das protagonistas). Para ilustrar a hibridização cultural desta personagem (usando preceitos de BHABHA, 1998), destacamos que essa nasceu numa vila Ojibwe e foi encontrada por um soldado, cujo peito serviu-lhe de alimento, filho de pai Quaker e de mãe poeta.

Partindo do questionamento levantado pelo narrador onisciente: "Who are you and who am I, the beader or the bit of colored glass sewn onto the fabric of earth?” (ERDRICH, 1998: 240), interrogamo-nos sobre assuntos que tangem à raça. Procedemos da seguinte forma: articulando as palavras do narrador com questões de raça e de etnia, perguntamo-nos se a profusão de cores apresentadas pelo romance confere ao texto a pluralidade de etnias que se encontraram nas Américas, mas que o poder hegemônico, através de mecanismos de opressão, acabou buscando subjugar, ofuscando tal multiplicidade, planejando convertê-la em um único organismo, em uma única forma de expressão. Como subversão, por meio da ironia, dessa supremacia branca (a cor hegemônica), o narrador traz: "the baby made its first sound [...] Roy could not touch it until the next day when he'd thought to wash himself all over and approach naked to diminish his whiteman's scent" (op. cit.: 05). Retomando a questão do "único organismo" (nos pressupostos deterministas de Durkheim, 1975), o conceito estabeleceu relações de poder, entre as etnias, e determinou o surgimento do conceito de raça (de base determinista biológica ${ }^{6}$ ) como desdobramento de inequidades de relações. Daí, pensamos: quais Tricksters encontramos em The Antelope Wife e como se inscrevem e atuam na resistência de algumas vozes nativoamericanas? Propomos uma análise da multivocalidade dos narradores do romance, revelando personagens que caminham entre o mundo físico dos humanos e o mundo mí(s)tico dos animais, em um tipo de simbiose, que representam o imaginário das narrativas nativo-americanas.

Para ilustrarmos essa passagem, trazemos o seguinte trecho: "[...] dream of a deer man. Dear head on his shoulders. Body of an athlete. Hooves striking flames from the tree roots." (ERDRICH, 1998: 53-54). O romance é narrado em partes, cada parte destaca um personagem, e que irão compor a narrativa central: todos os "tales" (estórias contadas/ouvidas, corroboram o storytelling) narram os antepassados de uma personagem para a qual todas as narrativas convergem. O trecho citado é narrado por uma menina aleatória (a princípio) e relata uma mulher que havia se envolvido

6 Partimos dos conceitos de raça apresentados por Kabemgele Munanga (2003), em uma palestra intitulada "Uma abordagem conceitual das noções de raça, racismo, identidade e etnia", conferida no $3^{\circ}$ Seminário Nacional sobre Relações Raciais e Educação - PENESB, 05/11/2003. 
com um homem híbrido, conforme se lê na passagem: "cabeça de veado sobre os ombros; cascos que jorram fogo". Percebemos uma simbiose na construção desse personagem: não se trata apenas de atributos do animal no homem (metonímia), mas partes do corpo de homem e partes do corpo de animal em sincronia (metáfora). Essa forma de trickster, a partir do discurso narrativo, confronta o paradigma ocidental, uma vez que rompe com as fronteiras do "real". A fortuna crítica eurocêntrica classifica uma narrativa dessa natureza como "literatura fantástica", visto que causa o estranhamento, pondo em xeque o princípio aristotélico da verossimilhança (TODOROV, 2012).

Sigamos, em outra passagem da mesma estória, em que se percebe:

[...] making love, their hearts were sunk deep in Earth and yet alert to the strangeness of who we are as human animals, as people reaching desperately through the wounds and synchronicities, as furtive unfortunates half drunk on the message of our mortality. (ERDRICH, 1998: 54).

Ressaltando a questão metáfora-metonímia na relação homem-animal, a primeira causa um efeito de sentido de condensação, enquanto que a segunda, de deslocamento (LACAN, 1985a). Sendo assim, o personagem encontra-se condensado ao animal, como um amálgama e o trecho acima alerta para esse sincronismo que é natural. Notar que o humano não é tratado, ontologicamente, com atributos de "homem", mas de animal: "nós somos como animais humanos" - o termo humano está em uma relação de adjetivo, portanto como um predicativo do sujeito, um acréscimo ao substantivo "animais". É sobre esse lugar de "estranheza" que circula o discurso contra hegemônico nesse romance. E essa visão de mundo, por meio do tropo poético apresentado no trecho em destaque, que entendemos o trickster como operacionalizador discursivo, como tropo da cultura. Este trickster rompe com a ordem, uma vez que transgride a cosmovisão hegemônica do homem como centro do universo. Assim, entendemos que nesse romance há formas de trickster, como de base cultural, através de figura discursiva e simbólica de origem diversa e (trans) culturalmente representada em textos de nativo-americanas.

Esta profusão de vozes/narradores parte de uma tradição de povos nativos, o storytelling, contrastando-se com a ordem canônica da linearidade narrativa, apoiada em toda uma visão cartesiana de mundo. Entendemos que tal característica marca a identidade de um grupo e, ao que nos interessa, as representações e construções identitárias através do texto literário. Neste ponto reside o caráter trickster usado por Erdrich: a enganação pelas narrativas memorialísticas e pelo mistério das práticas mágicas características pertencentes a seus grupos étnicos, elementos de difícil alcance dos outsiders (ELIAS; SCOTSON, 2000).

Para Elias; Scotson (200o), os habitantes de uma dada zona 1 (o "aldeamento") mantêm contato com os recém-chegados da zona 2 (o "loteamento"). Pelo fato de serem recém-chegados, são chamados de outsiders na terra daqueles estabelecidos. 
A descrição de uma comunidade da periferia urbana apresentada neste livro mostra uma clara divisão, em seu interior, entre um grupo estabelecido desde longa data e um grupo mais novo de residentes, cujos moradores eram tratados pelo primeiro como outsiders. O grupo estabelecido cerrava fileiras contra eles e os estigmatizava, de maneira geral, como pessoas de menor valor humano. Considerava-se que lhes faltava a virtude humana superior - o carisma grupal distintivo - que o grupo dominante atribuía a si mesmo (op. cit.: 32).

As problematizações que vão surgindo nas/através das análises dependem da perspectiva do observador: quem são os estabelecidos? Quem são os outsiders? Portanto, referimo-nos como estabelecidos os povos que habitavam a terra (na presente data, dita como) estadunidense e os outsiders, os povos que chegaram a partir do século XV.

No entanto, este é o lugar da resistência, da reivindicação de povos tradicionais que sofrem opressão. Do lado do poder hegemônico, aquele que estabelece e mantém as estruturas paradigmáticas das relações de poder, os nativos são relegados ao lugar de outsiders, sob a égide do eurocentrismo.

Para início das análises, trazemos uma informação importante para nossos argumentos que seguem.

By the mid-nineteenth century the Ojibwe were forced to live on reservations with few civil or legal rights. Traditional customs, religion, and language were first discouraged and then forbidden as the U.S. government attempted to force assimilation of native peoples into their European-based cultural model (Cornell, 1988) (DODGSON; STRUTHERS, 2003: 50-51, grifo nosso).

As autoras Dodgson; Struthers (2003) argumentam que os Ojibwe vêm passando os últimos cem anos se deslocando de um território de florestas e de vida nômade para o confinamento em reservas ou para o interior de cidades. Esses movimentos têm consequências devastadoras para os Ojibwe como as relações conflituosas, vez que o poder hegemônico não se caracteriza por uma convivência harmoniosa com povos tradicionais. Dessa objeção do Estado nascem, por exemplo, os processos de aculturação; ou tentativas, pois a resistência minimiza o apagamento total das bases culturais e identitárias do povo Ojibwe, especificamente. Portanto, entendemos que estas práticas de opressão e tentativa de apagamento cultural têm surtido efeitos distintos, desde o processo de hibridização cultural (BHABHA, 1998) à assimetria nas relações de poder, como a assimilação forçada de elementos culturais europeus.

Há que se considerar que essa escrita tem sido utilizada como forma de resistência pelos povos indígenas. Acrescentamos que os "Native Americans are not 
postcolonial peoples. Instead, today they remain colonized, suffering from internal colonialism." (WEAVER, 1997 apud SCHNEIDER, 2001: 38). Esta proposição surge com crítica, pois os textos literários desses povos surgem da resistência à colonização. Isto foi colocado pelo crítico de forma a discutir a tradição, costumes e literatura produzida por povos nativos, vez que sua produção cultural resultou da tensão entre nativos e povo europeu, no processo de colonização.

Os estudos e a crítica mais recentes nas Américas nesse território sugere o termo descolonial (ou decolonial). Isto porque é apresentada a questão de que "pós-colonial" reforça a égide colonial e o termo "descolonial" remete à retirada do pensamento colonial, portanto, ao processo de desligamento com o paradigma colonial e repressor, através do confronto com as relações de poder estabelecidas pela colonialidade. Segundo Costa (2014), "a opção descolonial, partindo das epistemologias geopolíticas e biográficas/corpo-políticas (seus dois pilares) privilegia o saber fronteiriço, ou seja, 'aquele que surge da exterioridade estruturada pela modernidade/colonialidade quando esta última se constitui como interioridade' (MIGNOLO, 2012, p. 29)" (COSTA, 2014: 260). Portanto, o uso do termo descolonial (decolonial) ressalta os conflitos das relações de poder de gênero, raça e classe que a colonialidade constitui e propõe novas epistemologias de enfrentamento político, social e cultural, tais como empoderamento, através do lugar de fala, descentralização das opressões discursivas institucionais.

Nesse sentido, a problematização central desta pesquisa reforça os enfrentamentos com o poder da ordem hegemônica. Para demonstrar esse debate, trazemos uma forma de trickster como agente de subversão (operador discursivo). Como exemplo do que pretendemos argumentar, lê-se no excerto:

First he tried to feed her a tiny piece of the rabbit [...] Nothing helped. It seemed, when he held her close upon his heart as women did, that the child grew angry with longing and desperately clung, rooted with its mouth, roared in frustration, until at last, moved to near insanity, Roy opened his shirt and put her to his nipple (ERDRICH, 1998: 06).

Scranton Roy é um homem branco e se vê deslocado de seu ambiente familiar, dos costumes europeus de seus ancestrais (Quakers da Pennsylvannia) para cuidar de uma bebê que encontra à beira de um rio. Na passagem acima, vemos a tentativa de Roy no sentido de alimentar a criança. Sem sucesso, e tentado pelos instintos e desespero, dá o próprio peito para amamentar a menina.

Notamos um diálogo mítico com a Eneida, de Virgílio (século I a. C.), em que uma loba encontra dois bebês à beira de um rio e alimenta Rômulo e Remo, fundadores de Roma, Império da Antiguidade e, junto à Grécia, berço da ocidentalidade. Além disso, percebemos uma ironia estrutural, como tropo da inversão: a loba (a fêmea) que alimenta dois outsiders na estória de Virgílio; o outsider do sexo masculino que alimenta a nativa (bebê), na estória de Erdrich. Além desse povo nativo/outsider, 
a inversão se dá no agente que oferece o peito, já que essa função seria biológica e culturalmente exercida pela fêmea/mulher. Trazemos os binômios macho/homem e fêmea/mulher por uso de contraste entre o mundo animal e o humano. No trecho citado, os papeis sociais foram invertidos e o instinto (o de alimentar uma criança indefesa e faminta; o de proteção e de cuidado), típicos dos animais, é exatamente o que humaniza Scranton Roy.

Prosseguimos argumentando que esta narrativa é típica de um mote muito caro à contação de estórias (storytelling): os mitos de fundação. Os ímpetos dos instintos, de um lado, o do homem de alimentar e, do outro, o da criança, o de saciar sua fome descontrolada humanizam o homem e a criança pelo elo da afetividade, pela luta pela permanência individual e da comunidade, conforme se vê em:

That made her wild for him. He couldn't remove her then and commenced to walk, holding her attached, toward a stand of cottonwood that wavered in the distance [...] He slung the blue beads around the baby's neck. Tied the cradle board onto his own back. Then, the man, child, and the dog struck farther into the wilderness (ERDRICH, 1998: o6-07, grifo nosso).

Observamos, com o auxílio do contexto da narrativa, que Roy não possuía nenhum conhecimento prévio, não tinha consciência, de como criar uma criança e cuidar de bebês em tenra idade. Argumentamos que seus instintos, ou sua memória afetiva de longo prazo e no nível do subconsciente, conduziam-no. A passagem grifada remete ao fato de a criança estar atrelada a ele, da qual não podia se apartar. $\mathrm{Na}$ frase anterior a narradora informa que ela (a criança) era uma selvagem aos olhos dele. Ora, se a bebê era selvagem e ele não conseguia "removê-la" de si, concluímos que havia algo ancestral que os unia e ele, em certa medida, era selvagem também, o que é confirmado, pois partem juntos para "uma vida cada vez mais selvagem".

Este conhecimento prévio a que nos referimos no parágrafo anterior estaria vinculado a um conjunto de saberes (culturais) de que se faz uso diante de qualquer práxis cultural. Neste caso, o de cuidar e alimentar uma criança. Percebemos uma série de ações que Roy executa, desde enrolar a criança em panos de algodão até fazer desse pano uma espécie de berço e levar a criança em suas costas para sua entrada no mundo selvagem.

Diante disso, trazemos uma informação dada por Dodgson; Struthers (2003): entre os Ojibwe era comum o cuidado dos bebês ser exercido por todos os membros da comunidade, homens ou mulheres, e nesse sentido todos recebiam orientações sobre tal prática pelos anciãos. As práticas de enrolar os bebês em panos de algodão e fazer uma espécie de berço e levá-los às costas eram sagradas para esse povo. Assim que os bebês nasciam tinham que ser enrolados e colocados no berço, que era feito por um membro próximo da família e esses berços permitiam que os bebês estivessem próximos de todas as atividades exercidas na comunidade ao longo dos dias. 
Além disso: "my mother would always say to wrap up the babies tightly, and they are calmer. It helps to keep their spirit in; when they are not wrapped their spirits go" (entrevista concedida por uma mulher Ojibwe e registrada em BAUMSLAG; MICHELS, 1995 apud DODGSON; STRUTHERS, 2003: 58). Além de envolvê-las em panos, as estudiosas argumentam que o amamentar é uma forma de amor e de oferecer cura e proteção aos bebês. Assim, podemos considerar que os elos, estando constantemente com o corpo pegado a alguém, recebendo o alimento daquele corpo ou de alguém do grupo, também estreita laços afetivos.

Com essa contextualização, voltamos ao trecho de Erdrich (1998: o6-07). Observamos várias ações que Roy toma para com a criança como se este tivesse sido ensinado por ela, ou pelos ancestrais dela, como se houvesse um elo mágico entre criança, homem e o ato de amamentação. Notamos tropos culturais (GATES JR., 1988) e a trickster, através da voz narrativa, aparece em forma de marca de territorialidade: a intervenções e relações do humano sobre o território (MARQUES, 20o9). Portanto, marcas de identidade.

Notamos que a trickster funciona como agente transgressor na corporalidade: o discurso narrativo coloca um homem do sexo masculino para romper com as fronteiras do próprio corpo e dos papeis sexuais estabelecidos pela sociedade para consumar um ato de extrema necessidade e de humanidade, no limite da sobrevivência. Portanto, e no lugar do mito, a transgressão acontece: notar que a trickster aqui traz uma forma humana que se apresenta em contrastes: 1- um homem que amamenta; 2- um soldado que age em prol da vida e não da morte. Podemos afirmar, que o tropo da ironia (RYAN, 1999) acontece e constrói, discursivamente, a trickster. A transgressão é o agenciamento nas relações de gênero: "He is a man, though he nourished her" (ERDRICH, 1998: 11, grifo nosso). O grifo destaca o termo "nourished" e não "breastfed": o primeiro está relacionado ao ato de alimentar; o segundo tem relação direta ao ato de amamentar. Embora ambos estejam no campo semântico do nutrir, apenas o segundo se refere a uma capacidade biológica atribuída à mulher.

Neste ponto específico, a ironia se aproxima do caráter burlesco da trickster: se o homem tem capacidade de nutrir alguém, por que o "apesar de"? Não seria uma alusão ao fato de homens não serem “capazes”, culturalmente, de alimentar/cuidar de alguém, conforme os modelos da cultura hegemônica? O fato de um homem cuidar de uma criança iria ferir as construções do patriarcado sobre a masculinidade? Estaria, assim, adentrando uma área que não lhe pertenceria? Dos cuidados e proteções? Um território do "feminino" na cultura original daquele sujeito? Lembremos que Scranton Roy era um soldado, um suposto tipo claro do "machão": "he looked around just in case there should be any witness to this act that seemed to him strange as anything that had happened in this sky-filled land" (ERDRICH, 1998: o6). Ressaltamos, depois desta explanação, a carga semântica que o fato de um homem ser capaz de abrir a camisa e pôr a boca de uma criança em seu mamilo para alimentá-la tem para uma sociedade sedimentada no patriarcado. 
Argumentamos que a trickster é a voz discursiva e não o personagem Scranton Roy, uma vez que o contexto da narração apresenta a ruptura pela voz narrativa (alótropos cômicos - VIZENOR, 1989) não no corpo do homem, e pela focalização em Matilda Roy, a menina que reivindica e faz funcionar a transgressão. O personagem homem sequer percebe essa ação verbal transgressora. Dessa forma, reivindicamos a construção do discurso narrativo e alguns elementos (e.g. narrador e personagem) como tricksters, diferentemente do que nos traz Gates Jr. (1988), por exemplo, que advoga as estruturas de tropos culturais produzidos por figuras trickster. Apoiamonos em Vizenor (1989) no que concerne a estruturas discursivas que constituem tricksters, apesar de discordarmos deste no que compete a sua afirmação que há um caráter cômico inerente aos alótropos que constituem tricksters.

Percebemos, em muitos momentos no romance em questão, a presença dos alótropos como voz narrativa e não como determinantes de tropos cômicos, pelo menos no que se refere ao cômico conforme defendido por Bakhtin (1987), através da estética da carnavalização e do elemento riso. Sabemos que o recorte de análises do autor é de textos tradicionais, pertencentes ao cânone. A discordância se dá ao aproximarmos este conceito de Vizenor (1989) para The Antelope Wife. Entendemos que textos contemporâneos apresentam mais flexibilidade de formas e estéticas que textos tradicionais. Portanto, a abordagem de nossas análises parte do conceito de Vizenor, porém não se sustenta nele.

Outra voz narrativa que trazemos éa personagem Ozhawashkwamashkodeykway /Blue Prairie Woman. Sabe-se que o ato de nomear, para muitas culturas, é a ação de criação: a coisa passa a existir a partir de seu nome, o "Fiat lux" bíblico se encontra no Gênesis, no início da criação. No entanto, para o povo Ojibwe, o ato de nomear, mesmo nesses momentos originais, é concretizado por meio de uma cerimônia, conforme se vê em:

Through Ojibwe ceremony the four directions, the earth, the moon and the moon's cycles, the seasons, the animals, water and the Creator are all acknowledged to remind the people to walk through life in a good way and respect our place within the fabric of all things. Birth, vision quests, prayer and many more are part of the ceremonial aspects of life for the Ojibwe people. Ceremony is more than a religious gathering; it is the way of life. ${ }^{7}$

O trecho acima descreve um rito sagrado de grande importância para os nascidos na comunidade Ojibwe. Trata-se do modo de vida desse povo e de sua cosmovisão. Logo, entendemos como um aspecto de existência dos Ojibwe. Como a narrativa em The Antelope Wife não é linear, sua recursividade no tempo narrativo - e da estrutura do storytelling - remonta ao tempo da memória que, segundo Bosi

7 Vide sítio eletrônico: <https://medium.com/spirit-canoe/anishinaabe-naming-ceremony-7289fc8f7 605>. Acesso em 18 out. 2018. Convidamos a observar uma cerimônia de nomeação Ojibwe neste link no Youtube: <https://www.youtube.com/watch?time_continue=96\&v=VKhi8qKWaIw>. 
(2009), é constituído por flashbacks e flashforwards, quebrando com a ordem linear da ocidentalidade. Já mencionamos a relevância da memória para a construção de textos orais e do caráter indispensável destes para a escrita de nativo-americanas/os.

Em meio a isso, o romance continua sua progressão textual citando a que veio antes, a matriarca, Ozhawashkwamashkodeykway: "Blue Praire Woman's name was covered with blood, burned with fire. Her name was old and exquisite and had belonged to many powerful mothers." (ERDRICH, 1998: 15). Esta que é a terra-mãe, a força e a voz da ancestralidade da menina perdida que bebe do leite do soldado branco, a que não tem nome/não passou pela cerimônia de nomeação dos Ojibwe, vem acompanhada pela morte. Seguem dois trechos para discussão:

The child lost in the raid was still nameless, still a half spirit, yet her mother mourned her for a solid year's time and nearly died of the sorrow (ERDRICH, 1998: 12, grifo nosso).

At night her breasts grew pale and hard and her milk impacted, spoiling in her, leaking out under her burnt clothes so that she smelled of sour milk and fire (ERDRICH, 1998: 12, grifo nosso).

Por esta criança, Matilda Roy, ter se perdido em meio ao incêndio criminoso cometido no seu lugar de pertencimento, esse sujeito foi deslocado de sua origem, tornou-se metade na vida, ou seja, nessa passagem percebemos o caráter da hibridização cultural e o sujeito alocado no entre-lugar (BHABHA, 1998): "still half spirit" - metade pertencente às raízes nativo-americanas, metade em algum lugar, perdida. Este trecho traz a marca da colonização, a forma violenta com que se deu a tomada do território dos primeiros povos (Anishinaabe) pelos europeus e a fragmentação do sujeito que se encontra em trânsito. O caráter híbrido de tricksters vai se encontrar na composição da personagem Matilda Roy.

No segundo trecho, ressaltamos aspectos simbólicos do leite materno e do fogo com a separação dolorosa de um ente nativo do seio de sua terra: Ozhawashkwamashkodeykway/Blue Prairie Woman representa a terra, as raízes da menina que se perdeu. Seus seios doem e perdem a cor (sangue) por não serem sugados pela boca da criança arrancada que se alimentaria dos elementos culturais de seu lugar de pertencimento, através do aleitamento. Nesse momento, sangue, leite e fogo simbolizam a ruptura dolorosa e violenta do sujeito nativo que, ao ser consumido pelo fogo do silenciamento. Somado a isso, a simbologia do fogo nesse trecho do romance nos remete aos antigos rituais com o fogo utilizado ainda hoje para "limpar" a terra, tirar tudo que ali havia. Esse processo de tentativa de apagamento de um povo (de suas tradições e costumes) é representado pelo fato da não nomeação da criança e esta se torna um sujeito metade espírito perambulante que será amamentado pela matriz cultural deslocada e em construção.

Notamos a constituição do hibridismo cultural em Matilda Roy que se perde de suas raízes e é amamentada por um sujeito nu, incipiente e incapaz de nutrir um ser 
cuja complexidade lhe é totalmente desconhecida. A própria menina, em tenra idade, parece mostrar domínio e autossuficiência diante da necessidade de se alimentar: "she seized him. Inhaled him. Her suck was fierce" (ERDRICH, 1998: o6), na verdade, devido à necessidade, ela provoca nele o jorrar do leite de que precisa. Como um bicho livre, Matilda Roy se movimenta na narrativa e suas atitudes são descritas como se esta assumisse o ethos de um animal: "Matilda's task was to spy on, hunt down, and follow the hens to their hidden nests." (ERDRICH, 1998: 09).

Ou no momento em que percebe a chegada de sua mãe (Blue Prairie Woman), esta também descrita com a perspicácia de um animal: "She heard the gentle approach that night, the scrawl of leaves, the sighing resonance of discovery" (ERDRICH, 1998: 18). Esses barulhos silenciosos noturnos são muito sutis para a percepção do ouvido de uma criança e ainda em estado de sono. E mais adiante, no leito de morte de sua mãe, Matilda/Other Side of the Earth, instintivamente apropriada de elementos culturais de sua matrilinearidade, canta as canções de sua mãe e aperta a mão dela com uma mão, ao passo que come o cachorro com a outra mão. Neste instante Blue Prairie Woman morre e "the antelope emerge from the band of the light at the world's edge" (ERDRICH, 1998: 19). Do ponto de vista simbólico, para povos nativo-americanos, os animais são espíritos e podem ser maus ou bons. De acordo com Thom-Lake (1997): "the antelope serves as a messenger and forewarns us of human behavior" (Ebook, posição 75-76).

Reconhecendo o termo antílope como tropo cultural, pois é um animal sagrado a muitos nativos, temos uma clara referência ao trickster como figura mítica. Porém, este tropo é utilizado neste romance como aparato simbólico, e não o caráter de significante linguístico, que conota o saber de um povo. Portanto, a figura trickster aqui é aquela que herda os "poderes" do antílope: Matilda/The Other Side of the Earth, uma vez que a sua matrilinearidade lhe confere as características do animal xamânico - o mensageiro, o que caminha entre os dois mundos. Para os povos nativo-americanos, a Natureza é sagrada e toda a força do Grande Espírito é soprada através de todas as coisas do universo. Para os sistemas de crença do povo tradicional nativo-americano, tudo é fonte de poder e deve ser reverenciado: "the traditional Native American believes that each linving thing in nature has a spirit of its own, in addition to being connected to and part of the Great Spirit" (THOM-LAKE, 1997, Ebook Posição o7-08). Sendo assim, a relação homem-animal é normal e harmônica porque é natural.

Como superestrutura do romance, notamos que se trata de uma narrativa histórica e mítica, ao mesmo tempo, em que pesa acontecimentos reais com a forma mítica de narrar esses fatos, fazendo registros culturais do povo Ojibwe como narrativa de fundação, em vistas à resistência dessa cultura que estava sendo dizimada. Episódios de imposição da cultura letrada e da religião eurocêntrica são retratados no romance, a exemplo de dois: 1- quando Matilda Roy mostra interesse em aprender o alfabeto proferido por uma mulher branca, de origem germânica, Miss Peace McKnight; 2quando do momento da nomeação das gêmeas: "They were named Mary, of course, for the good blue-robed woman, and Josephette, for the good husband. Only the 
Ojibwa tongue made Zosie of the latter name. Zosie. Mary" (ERDRICH, 1998: 15, grifo nosso).

Analisando esse último grifo, através do tropo da ironia proferido pela voz narrativa, percebemos a resistência de substratos culturais - nesse caso o linguístico - ao subverter a imposição do colonizador: a raiz linguística deriva da língua do branco, porém o registro fonológico imprime o extrato linguístico Ojibwe. Esta é uma forma de subversão da trickster Blue Prairie Woman, a narradora desta estória "A Dog Named Sorrow" (um cão chamado tristeza). Ela não rompe com a estrutura colonizadora, mas subverte valores ao demonstrar desinformação sobre os componentes da Família Sagrada cristã e ao imprimir a identidade linguística de seu povo, apesar de não transgredir com o sistema linguístico do colonizador.

Chegando na voz narrativa que, provavelmente, tece o fio das vozes narrativas que permeiam toda a obra, Cally Roy, destacamos a seguinte passagem:

\begin{abstract}
My name is Cally Roy, Ozhawasshkwamashkodeykway is what the spirits call me. All my life so far I've wondered about the meaning of my spirit name but nobody's told it, seen it, got ahold of my history flying past. Mama has asked, she has offered tobacco, even blankets, but my grandmas Mrs. Zosie Roy and Mary Shawano only nod at her, vague and shrewd-eyed, holding their tongues as they let their eyes wander [...] But once they get down to the city, it turns out they never stop moving. They are out, and out again. Impossible to track down. It's true, they are extremely busy women. (ERDRICH, 1998: 102).
\end{abstract}

Essa é a primeira e única personagem que se apresenta e narra em primeira pessoa sobre si. Ela está situada nos tempos contemporâneos da escrita do romance, anos 1990, em uma cidade do estado de Minneapolis. Apesar de estar inserido na cultura letrada, o trecho apresenta um grande desconhecimento de suas raízes e ancestralidade. As pessoas detentoras desse saber já são idosas e, em sua sabedoria, assumem o silêncio como forma de guardar o segredo do que pretendem proteger até verificarem a quem confidenciar suas estórias, até confiarem que, em meio a transições, podem dividir essa estória com a jovem. O questionamento que levantamos: teria dado certo o empreendimento da colonização para apagar as bases culturais do povo nativo-americano?

Acreditamos que a busca pelo saber e a insistência em narrar essas histórias personificadas nas ações verbais da suposta narradora central do romance demonstram a permanência da resistência, seja por pertencimento, o nome de espírito dela é o mesmo desde o de Blue Prairie Woman, seja pela curiosidade e insistência em conhecer. Nesse caso, a resistência da escrita, marcada pela multivocalização narrativa, apresenta formas de trickster que ora subverte, ora transgride a ordem hegemônica que não obtém sucesso na tentativa de silenciar um povo que se inscreve na memória de seus indivíduos, mesmo através de um momentâneo esquecimento. 
Entendemos que a complexidade da escrita de The Antelope Wife deve ser interpretada como uma colcha de retalhos feita a várias mãos, mas com um fio condutor que dá forma ao todo. O processo de multivocalização vai sendo construído por essas várias mãos e o fio condutor é a narradora, Cally Roy, que mistura sua voz com a dos personagens. Percebemos isso com a mudança de focalização que a narrativa vai introduzindo, à medida que a narradora vai apresentando vários personagens. Cada apresentação muda a focalização ao ponto de não se ter clara a voz do narrador (que se apresenta mais tarde na trama e assume o lugar de enunciadora utilizando o pronome em primeira pessoa). Este fato confere ao romance uma espécie de mise en abyme ${ }^{8}$ : uma estória central, localizada em Minneapolis/MN, que descortina micronarrativas, cujas focalizações conotam várias vozes narrativas. Trazemos as palavras de Erdrich ao falar sobre o romance:

While I was writing this story, my mother sponsored a bead group at her house,I became interested in the meditative quality of actually doing the beading. All of us would be sitting at a table beading and there would be this increasingly calm feeling of everybody being engrossed in the same task. It seemed to me as though it was an element of the world's creation; that this very female work that women did communally was somehow connected to the very beginnings of the world (ERDRICH, 2002)9.

O discurso de Erdrich conota o lugar de fala de que a escritora faz uso para a construção de sua narrativa. Além disso, corrobora nossa apreciação de que se trata de uma mise en abyme: a tessitura de cada miçanga como cada personagem, operacionalizado por uma tecedora que vai fazendo o contorno do desenho no tecido. A união dessas mulheres, sentadas à mesa de sua mãe, tecendo as miçangas (artesanato típico dos Ojibwe, conforme já se apresentou) representa a ancestralidade e a força feminina da tradição desse povo. A escritora reúne essa força poética e discursiva em The Antelope Wife, protagonizada por uma mulher contemporânea, de origem Ojibwe, que conduz as malhas da narrativa, junto a outras mulheres de seus antepassados.

Sobre a estrutura narrativa, percebemos a alternância de tempo fragmentado (flashbacks) e de focalização (vários pontos de vista do discurso narrativo que geram a profusão de vozes enunciativas). Somado a isso, há as relações imbricadas entre os personagens causando um efeito de incerteza e de definição quanto à particularidade

8 Termo cunhado por André Gide, em 1893, para relatar sobre uma narrativa que contém outras dentro de si. O termo é, muitas vezes, conhecido como "narrativa em abismo" e foi ampliado por Lucien Dällenbach que entende como "narrativa especular" (Vide: DÄLLENBACH, Lucien. Le Récit Spéculaire: essai sur la mise em abyme. Paris: Éditions du Seuil, 1977).

9 Uma palestra de Louise Erdrich concedida para alunos novatos do Departamento de Inglês da University of St. Thomas, com a supervisão da professora Patricia Petersen, em 01/o1/2002, Minneapolis, Minnesota/EUA. Disponível em: <https://news.stthomas.edu/the-antelope-wife/>. Acesso em 12/ jan./2019. 
de cada um. Na passagem que segue, percebemos a recursividade na escrita da autora: "Everything is all knotted up in a tangle. Pull one string of this family and the whole web will tremble" (ERDRICH, 1998: 259). A respeito da questão da não linearidade no tempo e nas personagens, Erdrich comenta: "I really wanted to have this sense - because of the beadwork weaving in and out - of weaving time and weaving the stories, because of the twins at the beginning of the novel weaving together the form of the world" (ERDRICH, 2002). Este efeito de sentido produzido propositalmente também faz alusão ao tempo da memória que é irregular e não linear, assim como das lembranças narradas. Esse tempo da memória confere ao texto o lugar do storytelling, da marca identitária de um povo através do texto.

$\mathrm{O}$ romance termina com uma alusão ao porvir que se entrelaça com o passado e permanece no presente. "All that followed. All that happened. All is as I have told" (ERDRICH, 1998: 240). Cally Roy, como trickster na narrativa se esconde através das diferentes tomadas de focalização, destacando outros personagens de sua ancestralidade; aparece como sujeito de enunciação no tempo contemporâneo de fala. Subverte com a inversão da visão de mundo hegemônica, pois dá voz às vozes silenciadas nativo-americanas e transgride a linearidade narrativa com o relato das experiências e estórias de personagens que rompem com o conceito ocidentalizado de tempo cronológico e personagem plano.

\section{Considerações Finais}

Resumindo nossas apreciações, demonstramos como o storytelling, prática ancestral de povos tradicionais, pode revelar tropos culturais do povo Ojibwe e marcar seu lugar de elocução como resistência de seus costumes, saberes e tradições. Esse traço da cultura Ojibwe é retrato em the Antelope Wife, através da narradora central, Cally Roy, que sendo trickster, revela as vozes de sua ancestralidade ao trançar um emaranhado de focalizações do passado que acabam por construir narrativas de formação, com seus mitos e símbolos, cujas representações permeiam os storytellings por gerações e, subvertendo os mitos europeus, estabelecem um lugar de fala que transgride a cosmovisão unitária e excludente do branco ocidental e colonizador.

Abrindo novo ciclo de cosmovisões... Há muito tempo havia um homem que acreditava no valor das pequenas e das grandes coisas. Andava por povoados, alertando as pessoas sobre a importância de valorizar todas as coisas, as grandes e as pequenas. Não acreditando em suas mensagens, o homem era zombado por todos. Até que um dia, uma mulher começou a acreditar em suas estórias e a seguilo para ouvir dele mais sobre esses mistérios da vida e das coisas e dos homens. Aí, essa mulher passou a dizer para as pessoas sobre a importância de respeitar todas as coisas, as grandes e as pequenas. Mas, as pessoas não acreditavam e a mulher passou a ser perseguida por suas crenças. Assim, ela fugiu do seu vilarejo e procurou o homem 
misterioso e casou-se ${ }^{10}$ com ele. Depois, dizem, ela descobriu que seu companheiro era um ser místico, um animal sagrado, um antílope ${ }^{11}$.

Dizem que os antílopes "Often play the role of messengers in Plains Indian mythology. In some tribes, the appearance of an antelope in a human settlement had the meaning of a message from the spirit world ${ }^{1213}$. Sendo assim, compreendemos que The Antelope Wife está inscrito na atemporalidade e para além dos espaços. A narradora central e as focalizações em diversas vozes ancestrais registram isso. Este mundo mí(s)tico que o romance retrata assegura a resistência do povo nativoamericano, mesmo séculos após a usurpação de seus territórios. As tricksters do romance subvertem o lugar do branco e transgridem as narrativas de formação eurocêntricas. Elas se manifestam de forma discursiva (multivocalizações narrativas) e através de tropos da cultura (animalização e metamorfoseamento). É de nosso costume afirmar que a colonização é um estupro, uma extirpação da alma. Porém, a reconstrução/restauração pós-trauma e a resistência dos povos originários nas Américas até a presente data demarca o lugar garantido pelos tempos imemoriais.

\section{Referências Bibliográficas:}

ABBOTT, Lyman (1998) The Antelope Wife: Literature and Its Times Supplement 1. Disponível em: <https://www.encyclopedia.com/arts/culture-magazines/antelopewife>. Acesso em 07 jan. 2019.

AGAMBEN, Giorgio (2004). The Open: man and animal. Translated by Kevin Attell. California: Stanford University Press.

ALAIMO, Stacy (2017). Feminismos Transcorpóreos e o Espaço Ético da Natureza. In: Revista de Estudos Feministas. Florianópolis, 25 (2): 562, p. 909-934.

1o To properly understand these stories, it is necessary to be aware of the nature of the animals that appear in Native American myths - specifically, that animal spirits frequently assume human form in the mythology of many Native American tribes. Just as nature gods like the Sun or Morning Star can marry mortals and father heroes, so can animal spirits like bears and wolves. They are not understood to be literal animals, but emissaries from the animal kingdom. Sometimes their human spouses are even surprised to learn their true identities later (showing clearly that they did not have the physical form of animals when they first met!). Vide sítio eletrônico: <http://www.native-languages.org/animalmarriage.htm>. Acesso em: 16 abr. 2019.

11 Narrativa adaptada de LACAPA, Michael. Antelope Woman. 1 ed. Cleveland/OH: Northland Publishing, 1992.

12 Disponível em: <http://www.native-languages.org/legends-antelope.htm>. Acesso em 16/abr./2019.

13 The Apache are natives of the Southwest deserts (particularly in Arizona, New Mexico, and Texas). Some Apache people were also located across the border in northern Mexico. One Apache band, the Na'ishan or Plains Apache, lived far away from the other Apaches, in what is now Oklahoma (vide sítio eletrônico: <www.bigorrin.org/apache_kids.htm>. Acesso em: 16 abr. 2019). 
BAKHTIN, Mikhail Mikhailovich (2006). Dialogic Imagination. Austin: University of Texas Press, 1983.

BEIDLER, Peter; BARTON, Gay (2006). A Reader's Guide to the Novels of Louise Erdrich. Missouri: University of Missouri Press.

BHABHA, Homi K (1998). O Local da Cultura. Trad. Myriam Ávila et al. Belo Horizonte: Editora da UFMG.

BOSI, Alfredo (1992). Dialética da Colonização. 3 ed. São Paulo: Companhia das Letras.

BOSI, Ecléa (2009). Memória e Sociedade: lembranças de velhos. 15 ed. São Paulo: Companhia das Letras.

COSTA, Claudia de Lima. (2014). Feminismos descoloniais para além do humano In: Revista de Estudos Feministas. vol.22, no.3. Florianópolis.

ELIAS, Norbert; SCOTSON, John L (200o). Os Estabelecidos e os Outsiders: sociologia das relações de poder a partir de uma pequena comunidade. Trad. Vera Ribeiro. Trad. do Posfácio à Edição Alemã: Pedro Süssekind. Ap. e Rev. Técnica: Federico Neiburg. Rio de Janeiro: Jorge Zahar Ed..

ERDRICH, Louise (1998). The Antelope Wife. New York: Harper Perennial Publishers.

DODGSON, Joan; STRUTHERS, Roxanne (2003). Traditional Breastfeeding Practices of the Ojibwe of Northern Minnesota. In: Health Care for Women International. n. 24, v.1, p. 49-61.

GATES JR., Henry Louis (1988). The Signifying Monkey: a theory of African-American literary criticism. New York: Oxford University Press.

HEIDEGGER, Martin (1967). Carta Sobre o Humanismo. Rio de Janeiro: Tempo Brasileiro.

HEIDEGGER, Martin (1988). Ser e Tempo. Petrópolis: Vozes.

LACAN, Jacques (1985). O Seminário - Livro 2; o eu na teoria de Freud e na técnica da psicanálise (1954-1955). Rio de Janeiro: Jorge Zahar.

MARQUES, Amanda Christinne Nascimento (2009). Território de Memória e Territorialidades da Vitória dos Potiguara da Aldeia Três Rios. Dissertação de Mestrado. João Pessoa: UFPB. 
RYAN, Allan (1999). The Trickster Shift - humour and irony in contemporary Native Art. Toronto: UBC Press.

SCHNEIDER, Liane (2001). Race, Gender and Culture: reconstructions of 'America' by Native Women writers. Tese de Doutorado. Florianópolis: Universidade Federal de Santa Catarina.

SCHWARCZ, Lilia Moritz (1993). O Espetáculo das Raças. Cientistas, instituições e questão racial no Brasil, 1870-1930. São Paulo: Companhia das Letras.

SLOTERDIJK, Peter (200o). Regras para o Parque Humano: uma resposta à carta de Heidegger sobre o humanismo. Trad. José Oscar de Almeida Marques. São Paulo: Estação Liberdade.

THOM-LAKE, Bobby (Medicine Grizzly Bear) (1997). Spirits of the Earth: a guide to Native American nature symbols, stories, and ceremonies. New York: A Plume Book/ Penguin Group.

TODOROV, Tzvetan (2012). Introdução à Literatura Fantástica. Col. Debates 98. São Paulo: Perspectivas.

VIZENOR, Gerald (1989). Narrative Chance: Postmodern Discourse on Native American Indian Literatures. Albuquerque: University of New Mexico. 